\title{
Communication
}

\section{Non-Covalent Interactions in the Crystal Structure of Methyl 4-Hydroxy-3-Nitrobenzoate}

\author{
Xin-Ling Fu ${ }^{1}{ }^{*}$, Jiang-Sheng $\mathrm{Li}^{2}$ and Jim Simpson ${ }^{3}$ \\ 1 Changsha Medical University, Changsha 410219, China \\ 2 School of Chemistry \& Biological Engineering, Changsha University of Science and Technology, \\ Changsha 410114, China; E-Mail: js_li@yahoo.com.cn \\ 3 Department of Chemistry, University of Otago, P. O. Box 56, Dunedin 9054, New Zealand; \\ E-Mail: jsimpson@alkali.otago.ac.nz \\ * Author to whom correspondence should be addressed; E-Mail: xinlingfu@ gmail.com; \\ Tel.: +86-731-85258733; Fax: +86-731-85258733.
}

Received: 18 April 2012; in revised form: 22 May 2012 / Accepted: 1 June 2012 /

Published: 12 June 2012

\begin{abstract}
Methyl 4-hydroxy-3-nitrobenzoate, (I), $\mathrm{C}_{8} \mathrm{H}_{7} \mathrm{NO}_{5}$, crystallizes with two unique molecules, $\mathrm{A}$ and $\mathrm{B}$, in the asymmetric unit of the triclinic unit cell. The space group was assigned as P-1, with lattice parameters $a=0.72831(15), b=1.0522(2), c=1.1410(2) \mathrm{nm}$, $\alpha=83.38(3), \beta=80.83(3), \gamma=82.02(3)^{\circ}, Z=4, V=0.8510(3) \mathrm{nm}^{3}, M_{\mathrm{r}}=197.15$, $D_{c}=1.539 \mathrm{~g} / \mathrm{m}^{3}, \mu=0.131 \mathrm{~mm}^{-1}, F(000)=408, R=0.1002$ and $w R=0.2519$. In the crystal structure, 12 hydrogen bonding and two $\pi$-stacking interactions link the molecules into infinite stacked sheets parallel to (101).
\end{abstract}

Keywords: hydroxynitrobenzoate ester; crystal structure; noncovalent interactions; hydrogen bonding; $\pi$-stacking

\section{Introduction}

Weak noncovalent interactions play a significant role in biological or biomimetic systems as well as in artificial supramolecular structures. They can stabilize the three-dimensional structure of large molecules, such as proteins and nucleic acids, and are involved in many biological processes [1]. Also, the noncovalent bond is the dominant contact between supramolecules in supramolecular chemistry [2]. These forces commonly include both classical and non-classical hydrogen bonding, $\pi-\pi$ and $\mathrm{C}-\mathrm{H} \ldots \pi$ 
interactions together with hydrophobic forces, van der Waals interactions, and electrostatic effects [2]. The study of these non-covalent interactions is crucial to understanding the structures of organic crystals, drug binding, and many biological processes. Experimentally, these interactions are often seen in complex environments, where it can be difficult to pick out only the interaction of interest. Theoretically, they feature shallow potential energy surfaces and require very accurate quantum-mechanical modeling for reliable predictive results. In the structure of methyl 4-hydroxy-3-nitrobenzoate, $\mathrm{C}_{8} \mathrm{H}_{7} \mathrm{NO}_{5}(\mathrm{I})$, determined by single crystal X-ray analysis, we examine the variety of non-covalent interactions that lead to the overall stability of the crystal structure.

\section{Results and Discussion}

Methyl 4-hydroxy-3-nitrobenzoate (I) crystallizes with two unique molecules in the asymmetric unit of the triclinic unit cell (Figure 1). The two molecules are closely similar and overlay with an rms deviation of $0.0193 \AA$ and a maximum deviation of $0.0398 \AA$ [3]. Both the N1 O1 O2 nitro and C7 O4 O5 C8 methyl ester substituents lie close to the planes of the benzene rings in both molecules, with dihedral angles between the planes of $6.1(6)^{\circ}$ and 10.5 (3) ${ }^{\circ}$ in molecule A and 6.2 (7) ${ }^{\circ}$ and $10.4(2)^{\circ}$ in molecule B. Intramolecular $\mathrm{O} 3 \mathrm{~A}-\mathrm{H} 3 \mathrm{~A} \cdots \mathrm{O} 2 \mathrm{~A}$ and $\mathrm{O} 3 \mathrm{~B}-\mathrm{H} 3 \mathrm{~B} \cdots \mathrm{O} 2 \mathrm{~B}$ hydrogen bonds, Table 1, generate planar $\mathrm{S}(6)$ rings [4]. Rms deviations from these ring planes are $0.035 \AA$ for molecule $\mathrm{A}$ and $0.023 \AA$ for molecule B suggesting that these contacts contribute to the overall planarity of both molecules. A search of the Cambridge Database [5] reveals two isomeric forms of (I), namely methyl 2-hydroxy-3-nitrobenzoate (II) [6] and methyl 2-hydroxy-5-nitrobenzoate (III) [7] together with the closely related methyl 2-hydroxy-3,5-dinitrobenzoate (IV) [8]. In all three similar structures, intramolecular $\mathrm{O}-\mathrm{H}$... O hydrogen bonds involve the $\mathrm{OH}$ substituent and either a nitro or carbonyl oxygen and ensure that the molecules adopt reasonably planar conformations. Interestingly, for (II) and (IV), where a choice of $\mathrm{O}$ acceptor atom is possible due to the relative placements of the nitro and methyl ester substituents, the carbonyl $\mathrm{O}$ atom of the methyl ester is the preferred acceptor. In addition, the structures of a number of derivatives in which the phenol $\mathrm{H}$ atom has been replaced to form alkyl [9] and aryl [10,11] ether derivatives have also been reported.

Figure 1. The asymmetric unit of (I) with displacement ellipsoids for the non-hydrogen atoms drawn at the $50 \%$ probability level, and intramolecular hydrogen bonds are drawn as dashed lines in molecules A and B.

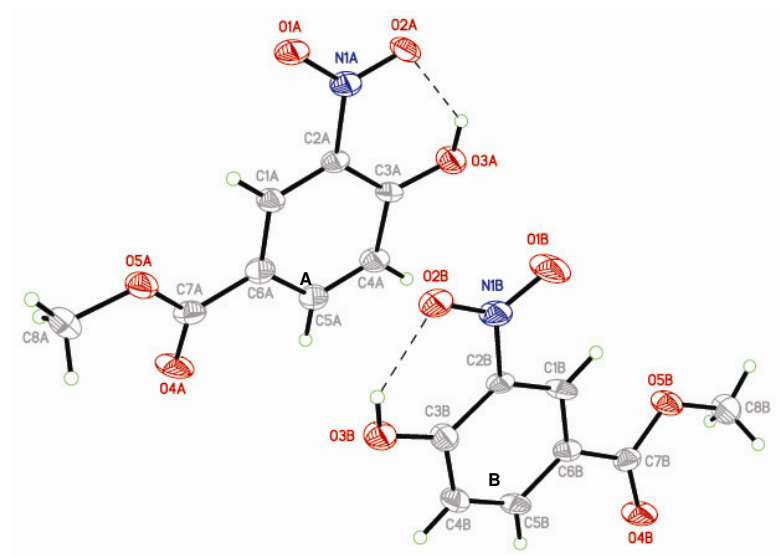


Table 1. Hydrogen-bond geometries for compound I.

\begin{tabular}{|c|c|c|c|c|}
\hline Bond & D-H & $\mathbf{H} \cdots \mathbf{A}$ & D $\cdots A$ & D-H $\cdots A$ \\
\hline $\mathrm{O} 3 \mathrm{~A}-\mathrm{H} 3 \mathrm{~A} \cdots \mathrm{O} 2 \mathrm{~A}$ & $0.828(11)$ & $1.94(4)$ & $2.585(5)$ & $134(5)$ \\
\hline $\mathrm{O} 3 \mathrm{~B}-\mathrm{H} 3 \mathrm{~B} \cdots \mathrm{O} 2 \mathrm{~B}$ & $0.831(11)$ & $1.91(4)$ & $2.584(5)$ & $137(5)$ \\
\hline $\mathrm{C} 8 \mathrm{~A}-\mathrm{H} 8 \mathrm{AB} \cdots \mathrm{O} 3 \mathrm{~A}^{\mathrm{i}}$ & 0.96 & 2.62 & $3.372(7)$ & 136 \\
\hline $\mathrm{C} 8 \mathrm{~A}-\mathrm{H} 8 \mathrm{AA} \cdots \mathrm{O} 3 \mathrm{~A}^{\mathrm{ii}}$ & 0.96 & 2.61 & $3.441(7)$ & 145 \\
\hline $\mathrm{C} 4 \mathrm{~A}-\mathrm{H} 4 \mathrm{~A} \cdots \mathrm{O} 4 \mathrm{~B}^{\mathrm{iii}}$ & 0.93 & 2.41 & $3.136(7)$ & 135 \\
\hline $\mathrm{O} 3 \mathrm{~A}-\mathrm{H} 3 \mathrm{~A} \cdots \mathrm{O} 1 \mathrm{~B}^{\mathrm{iv}}$ & $0.828(11)$ & $2.30(5)$ & $2.896(5)$ & $129(5)$ \\
\hline $\mathrm{C} 1 \mathrm{~A}-\mathrm{H} 1 \mathrm{~A} \cdots \mathrm{O} 2 \mathrm{~B}^{\mathrm{v}}$ & 0.93 & 2.56 & $3.483(6)$ & 174 \\
\hline $\mathrm{C} 4 \mathrm{~B}-\mathrm{H} 4 \mathrm{~B} \cdots \mathrm{O} 4 \mathrm{~A}^{\mathrm{vi}}$ & 0.93 & 2.49 & $3.327(6)$ & 150 \\
\hline $\mathrm{C} 1 \mathrm{~B}-\mathrm{H} 1 \mathrm{~B} \cdots \mathrm{O} 2 \mathrm{~A}^{\mathrm{iv}}$ & 0.93 & 2.59 & $3.509(6)$ & 168 \\
\hline $\mathrm{O} 3 \mathrm{~B}-\mathrm{H} 3 \mathrm{~B} \cdots \mathrm{O} 1 \mathrm{~A}^{\mathrm{v}}$ & $0.831(11)$ & $2.28(4)$ & $2.863(5)$ & $128(5)$ \\
\hline $\mathrm{C} 8 \mathrm{~B}-\mathrm{H} 8 \mathrm{BB} \cdots \mathrm{O} 3 \mathrm{~B}{ }^{\mathrm{vii}}$ & 0.96 & 2.50 & $3.282(6)$ & 139 \\
\hline $\mathrm{C} 8 \mathrm{~B}-\mathrm{H} 8 \mathrm{BA} \cdots \mathrm{O} 3 \mathrm{~B}{ }^{\mathrm{viii}}$ & 0.96 & 2.70 & $3.475(7)$ & 139 \\
\hline
\end{tabular}

Symmetry codes: ${ }^{\mathrm{i}} x, y+1, z ;{ }^{\mathrm{ii}}-x,-y+1,-z+1 ;{ }^{\mathrm{iii}}-x,-y,-z+2 ;{ }^{\mathrm{iv}}-x+1,-y,-z+1 ;{ }^{\mathrm{v}}-x+1$, $-y+1,-z+1 ;{ }^{\mathrm{vi}}-x,-y+1,-z+2 ;{ }^{\mathrm{vii}} x, y-1, z ;{ }^{\text {viii }}-x+1,-y,-z+2$.

In the crystal structure two sets of centrosymmetric dimers form through $\mathrm{O} 3 \mathrm{~A}-\mathrm{H} 3 \mathrm{~A} \cdots \mathrm{O} 1 \mathrm{~B}$ hydrogen bonds together with $\mathrm{C} 1 \mathrm{~B}-\mathrm{H} 1 \mathrm{~B} \cdots \mathrm{O} 2 \mathrm{~A}$ interactions and $\mathrm{O} 3 \mathrm{~B}-\mathrm{H} 3 \mathrm{~B} \cdots \mathrm{O} 1 \mathrm{~A}$ and $\mathrm{C} 1 \mathrm{~A}-\mathrm{H} 1 \mathrm{~A} \cdots \mathrm{O} 2 \mathrm{~B}$ contacts (Figure 2). The formation of each dimer generates $R_{2}^{2}$ (11) rings [4]. Additional weak $\mathrm{C}-\mathrm{H} \cdots \mathrm{O}$ contacts link these dimers into sheets in the $b c$ plane. $\pi$-Stacking interactions are also found between the aromatic rings of adjacent molecules, linking them in a head to tail fashion (Figure 3). Centroid to centroid distances are 3.713 (3) for the A and 3.632 (3) for the B molecules. These interactions are augmented by additional weak inversion related $\mathrm{C} 8 \mathrm{~A}-\mathrm{H} 8 \mathrm{AA} \cdots \mathrm{O} 3 \mathrm{~A}$ and $\mathrm{C} 8 \mathrm{~B}-$ H8BA … $\mathrm{O} 3 \mathrm{~B}$ contacts forming $\mathrm{AA}$ and $\mathrm{BB}$ dimers and generating $\mathrm{R}^{2}{ }_{2}(18)$ rings. The two sets of dimers combine to form sheets parallel to the (101) plane (Figure 4). Similar sheet formation is also common to the crystal structures of the isomeric forms (II) and (III) [6,7]; significant C-H...O hydrogen bonds are found in both structures forming layers that are further connected by weak $\pi \ldots \pi$ contacts.

Figure 2. Centrosymmetric dimers forming sheets in the $b c$ plane with hydrogen bonds drawn as dashed lines.

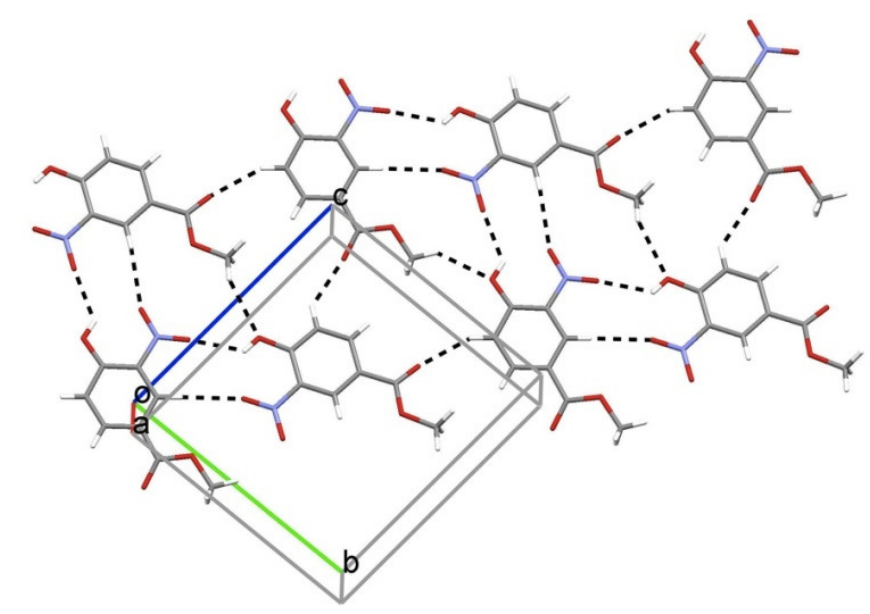


Figure 3. Centrosymmetric dimers formed by $\pi \cdots \pi$ contacts (dotted lines) and weak $\mathrm{C}-\mathrm{H} \cdots \mathrm{O}$ interactions dashed lines. The red spheres represent centroids of the benzene rings in the A molecules and the blue sphere those in the B molecules.

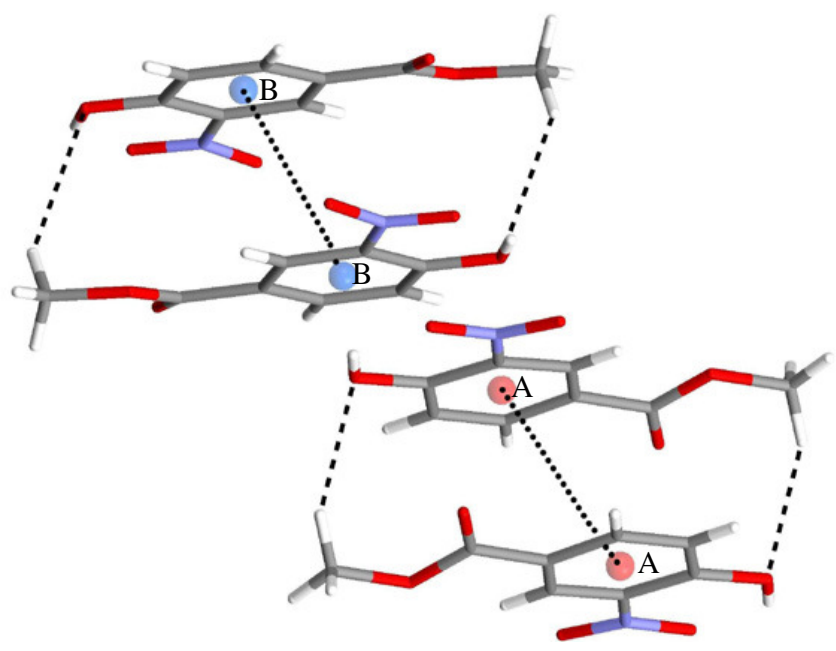

Figure 4. Crystal packing for (I) viewed along the $b$ axis with hydrogen bonds drawn as dashed lines.

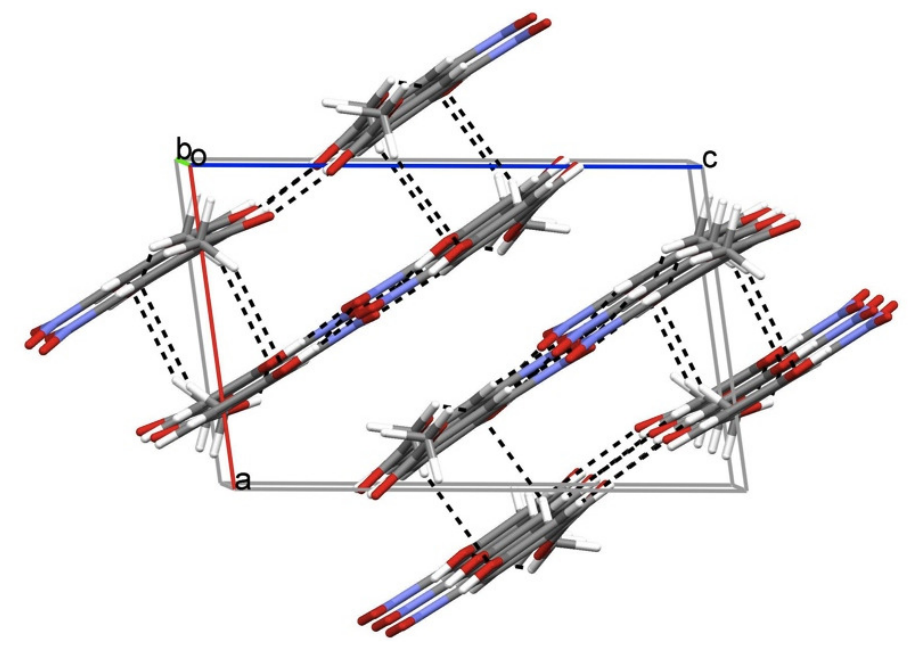

\section{Experimental Section}

Synthesis of methyl 4-hydroxy-3-nitrobenzoate (I). Cerium (IV) ammonium nitrate (CAN) (10.96 g, $20 \mathrm{mmol})$ was added to a mixture of methyl 4-hydroxybenzoate $(1.5 \mathrm{~g}, 10 \mathrm{mmol})$ and $\mathrm{NaHCO}_{3}(3.5 \mathrm{~g})$ in anhydrous MeCN $(60 \mathrm{~mL})$ at room temperature while stirring. The reaction mixture was then stirred at room temperature for a further $30 \mathrm{~min}$. The resulting mixture was filtered, washed with water, and extracted with ethyl acetate $(3 \times 25 \mathrm{~mL})$. The combined extracts were dried over anhydrous $\mathrm{Na}_{2} \mathrm{SO}_{4}$, and the solvent removed to furnish the title compound (70\%). m.p. $74-76{ }^{\circ} \mathrm{C} .{ }^{1} \mathrm{H}$ NMR (DMSO- $d_{6}$, $400 \mathrm{MHz}, \mathrm{ppm}) \delta 8.39(\mathrm{~d}, J=1.7 \mathrm{~Hz}, 1 \mathrm{H}), 8.06(\mathrm{dd}, J=8.7 \mathrm{~Hz}, 1.7 \mathrm{~Hz}, 1 \mathrm{H}), 7.23(\mathrm{dd}, J=8.7 \mathrm{~Hz}$, $1.7 \mathrm{~Hz}, 1 \mathrm{H}$ ), 3.85 (s, $3 \mathrm{H}$ ). ${ }^{13} \mathrm{C}$ NMR (DMSO- $\left.d_{6}, 100 \mathrm{MHz}, \mathrm{ppm}\right) 165.4,156.7,137.5,136.0,127.6$,

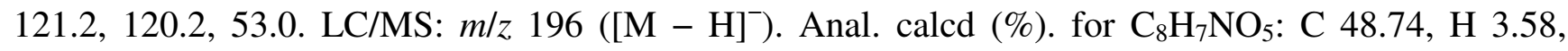
$\mathrm{N}$ 7.10. Found (\%): C 48.66, H 3.51, N 7.03. Colorless plate-like crystals of (I) were grown from 
a solution of petroleum ether and ethyl acetate $(1: 1, \mathrm{v} / \mathrm{v})$ by slow natural evaporation at room temperature.

$X$-ray Data Collection and Structure Solution. A single crystal of (I) with dimensions $0.20 \mathrm{~mm} \times 0.18 \mathrm{~mm} \times 0.04 \mathrm{~mm}$ was selected for data collection performed on a Rigaku Saturn CCD area detector $(\lambda=0.71073 \AA)$ [12] using the $\omega-2 \theta$ scan mode. A total of 5670 reflections were collected in the range $1.8 \leq \theta \leq 26.1^{\circ}$. Of these 2959 were independent $\left(R_{\text {int }}=0.129\right)$, and 1408 were considered to be observed with $I>2 \sigma(I)$ and used in the succeeding refinement. The structure was solved by direct methods and refined on $F^{2}$ by full matrix least-squares using the SHELXTL program [13]. The H3A and H3B atoms of the hydroxy groups were located in a difference Fourier map and their coordinates refined with $U_{\text {iso }}=1.5 U_{\text {eq }}(\mathrm{O})$. All other $\mathrm{H}$-atoms were refined using a riding model with $\mathrm{d}(\mathrm{C}-\mathrm{H})=0.93 \AA, U_{\text {iso }}=1.2 U_{\text {eq }}(\mathrm{C})$ for aromatic and $0.96 \AA, U_{\text {iso }}=1.5 U_{\text {eq }}(\mathrm{C})$ for $\mathrm{CH}_{3} \mathrm{H}$ atoms. Goodness-of-fit on $F^{2}$ is 0.951. $R=0.1003$ and $w R 2=0.2519$, with $\left(w=1 /\left[\sigma^{2}\left(F_{o}^{2}\right)+(0.0965 P)^{2}\right]\right.$, where $\left.P=\left(F_{o}{ }^{2}+2 F_{c}{ }^{2}\right) / 3\right) .(\Delta \rho)_{\max }=0.43,(\Delta \rho)_{\min }=-0.45 \mathrm{e} / \AA^{3}$. The crystal was very weakly diffracting with less than half of the measured reflections with $\mathrm{I}>2 \sigma(\mathrm{I})$ and a high $\mathrm{R}$ (int). In addition, anisotropic refinement led to elongations of displacement ellipsoids for some atoms and restraints were used in order to minimise these effects. The final residuals are therefore somewhat higher than normal as a result, but this does not markedly affect the integrity of the overall structure.

\section{Conclusions}

The molecular and crystal structure of methyl 4-hydroxy-3-nitrobenzoate (I) is reported. The structure is stabilised by an extensive set of twelve hydrogen bonding and two $\pi$-stacking interactions.

\section{Acknowledgments}

Financial support from the Scientific Research Fund of Hunan Provincial Education Department (10B012 \& 10W017) is gratefully acknowledged.

\section{References}

1. Lodish, H.; Berk, A.; Kaiser, C.A.; Krieger, M.; Scott, M.P.; Bretscher, A.; Ploegh, H.; Matsudaira, P. Molecular Cell Biology, 6th ed.; W.H. Freeman Publishers: New York, NY, USA, 2007; pp. 29-56.

2. Steed, J.W.; Atwood, J.L. Supramolecular Chemistry, 2nd ed.; John Wiley \& Sons Ltd.: Chichester, UK, 2000; pp. 27-36.

3. Macrae, C.F.; Bruno, I.J.; Chisholm, J.A.; Edgington, P.R.; McCabe, P.; Pidcock, E.; Rodriguez-Monge, L.; Taylor, R.; van de Streek, J.; Wood, P.A. Mercury CSD 2.0-New features for the visualization and investigation of crystal structures. J. Appl. Cryst. 2008, 41, 466-470.

4. Bernstein, J.; Davis, R.E.; Shimoni, L.; Chang, N.-L. Patterns in hydrogen bonding: Functionality and graph set analysis in crystals. Angew. Chem. Int. Ed. Engl. 1995, 34, 1555-1573.

5. Allen, F.H. The Cambridge structural database: A quarter of a million crystal structures and rising. Acta Cryst. 2002, B58, 380-388. 
6. Liu, Y.-Z.; Li, Y.-X.; Zhang, L.; Li, X. Methyl 2-hydroxy-3-nitrobenzoate. Acta Cryst. 2009, E65, doi:10.1107/S1600536809024301.

7 Jin, L.-F.; Xiao, F.-P. Methyl 5-nitrosalicylate. Acta Cryst. 2005, E61, o1107-o1108.

8 Jin, L.-F.; Xiao, F.-P.; Wang, C.-G. Methyl 3,5-dinitrosalicylate. Acta Cryst. 2004, E60, o1593-01594.

9. Zhao, S.-Y.; Mou, S.-W.; Zhao, S.-H.; Qin, W.-M. Methyl 3-nitro-4-propoxybenzoate. Acta Cryst. 2007, E63, doi:10.1107/S1600536807028619.

10. Gopal, R.; Chandler, W.D.; Robertson, B.E. Conformations of bridged diphenyls. XV. Crystal structure of (4-carbomethoxy-2-nitrophenoxy)benzene and the effect of intramolecular interactions in nitro substituents. Can. J. Chem. 1980, 58, 658-663.

11. Van der Heijden, S.P.N.; Griffith, E.A.H.; Chandler, W.D.; Robertson, B.E. Conformations of bridged diphenyls. VII. Crystal structure of 2-(4'-Carbomethoxy-2'-nitrophenoxy)-1,3,5trimethylbenzene. Can. J. Chem. 1975, 53, 2084-2092.

12. Rigaku/MSC. CrystalClear; Rigaku/MSC Inc.: The Woodlands, TX, USA, 2005.

13. Sheldrick, G.M. A short history of SHELX. Acta Cryst. 2008, A64, 112-122.

(C) 2012 by the authors; licensee MDPI, Basel, Switzerland. This article is an open access article distributed under the terms and conditions of the Creative Commons Attribution license (http://creativecommons.org/licenses/by/3.0/). 